\title{
Endoscopic submucosal dissection of a subepithelial neuroendocrine tumor located in the duodenum using a countertraction technique
}

Endoscopic submucosal dissection (ESD) is the technique of choice to remove large superficial neoplasms of the esophagus, stomach, colon, and rectum [1]. In the duodenum, for non-ampullary lesions, it has been associated with a high risk of perforation [2] owing to the relative thinness of the duodenal wall. Data with regard to ESD for subepithelial lesions are scarce. One study described a low rate of curative treatment for duodenal neuroendocrine tumors (NETs), but few patients were included [3]. Techniques such as countertraction using a rubber band [4] and anchoring the clips to close the scar [5] can be considered to secure the procedure.

We herein report the case of a 58-yearold man with a non-ampullary duodenal subepithelial NET of $9 \mathrm{~mm}$ that was removed by ESD ( $\downarrow$ Video 1 ). First, a circumferential incision was performed within the mucosa. Countertraction with two clips and a rubber band was then used to facilitate dissection of the lesion ( $\triangleright$ Fig. 1 a). The lesion was removed en bloc. After the procedure, the scar was closed by anchoring the clips: small mucosal incisions were performed around the scar ( Fig. $\mathbf{1}$ b) to allow better grip for the clip at each edge of the scar with-

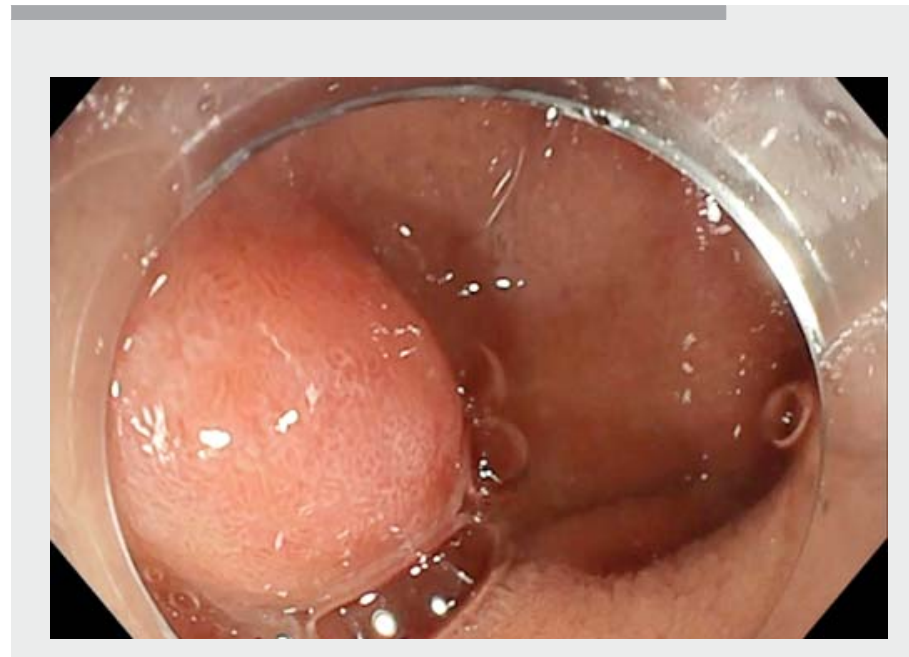

Video 1 Endoscopic submucosal dissection of a subepithelial neuroendocrine tumor located in the duodenum using a countertraction technique.

out their slipping ( $\triangleright$ Fig. 1 c). The patient was discharged the day after the procedure without experiencing any adverse events.

The pathology report revealed a well differentiated NET, G2 (Ki-67 index 4\%; mitotic count 1), without perineural invasion but with lymphatic emboli. The NET was completely resected by the procedure. Surveillance was determined to be the appropriate further management by a NET multidisciplinary team.

This case highlights the feasibility of ESD for subepithelial NETs located in the duodenum. It also illustrates the countertraction technique and closure of the scar by anchoring the clips to secure the procedure. This must however only be done in highly selected patients and by skilled endoscopists.
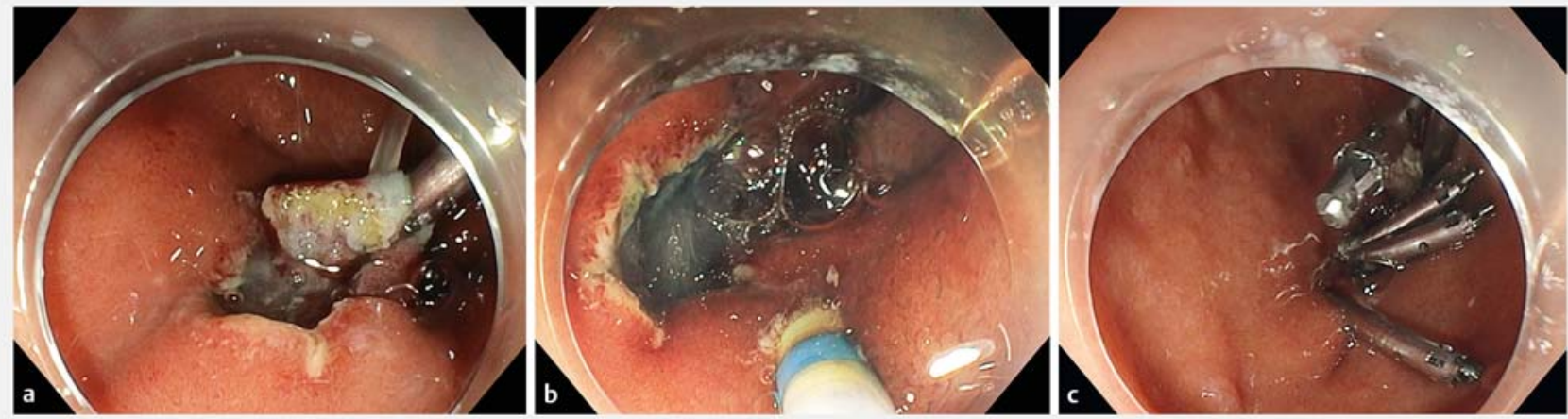

Fig. 1 Endoscopic views showing: a countertraction with two clips and a rubber band being used to facilitate dissection of the lesion; b small mucosal incisions that were made around the scar to allow better grip for the clips at each edge of the scar without their slipping; c the appearance of the closed scar. 


\section{Competing interests}

The authors declare that they have no conflict of interest.

The authors

Thomas Lambin ${ }^{1,2}$, Clara Yzet ${ }^{3}$, Jérémie Albouys $^{4}$, Pierre Lafeuille ${ }^{1}$, Florian Rostain ${ }^{1}$, Jérôme Rivory ${ }^{1}$, Mathieu Pioche1,2

1 Gastroenterology and Endoscopy Unit, Pavillon L, Edouard Herriot Hospital, Lyon, France

2 Inserm U1032, Labtau, Lyon, France

3 Department of Gastroenterology, Amiens University Hospital, Amiens, France

4 Gastroenterology and Endoscopy Unit, CHU Dupuytren, Limoges, France

\section{Corresponding author}

\section{Thomas Lambin, MD}

Endoscopy Unit - Digestive Disease Department, Pavillon L - Hôpital Edouard Herriot, 69437 Lyon, France thomaslambin@hotmail.fr
[1] Pimentel-Nunes P, Dinis-Ribeiro M, Ponchon $T$ et al. Endoscopic submucosal dissection: European Society of Gastrointestinal Endoscopy (ESGE) Guideline. Endoscopy 2015; 47 : 829-854

[2] Watanabe D, Hayashi H, Kataoka Y et al. Efficacy and safety of endoscopic submucosal dissection for non-ampullary duodenal polyps: A systematic review and meta-analysis. Dig Liver Dis 2019; 51: 774-781

[3] Kobara H, Miyaoka Y, Ikeda Y et al. Outcomes of endoscopic submucosal dissection for subepithelial lesions localized within the submucosa, including neuroendocrine tumors: a multicenter prospective study. J Gastrointest Liver Dis 2020; 29: 41-49

[4] Jacques ], Charissoux A, Bordillon P et al. High proficiency of colonic endoscopic submucosal dissection in Europe thanks to countertraction strategy using a double clip and rubber band. Endosc Int Open 2019; 7: E1166-E1174

[5] Otake Y, Saito Y, Sakamoto T et al. New closure technique for large mucosal defects after endoscopic submucosal dissection of colorectal tumors (with video). Gastrointest Endosc 2012; 75: 663-667
Bibliography

Endoscopy 2022; 54: E230-E231

DOI 10.1055/a-1492-2362

ISSN 0013-726X

published online 31.5.2021

(c) 2021. Thieme. All rights reserved.

Georg Thieme Verlag KG, Rüdigerstraße 14, 70469 Stuttgart, Germany

\section{ENDOSCOPY E-VIDEOS}

https:|/eref.thieme.de/e-videos

口回 Endoscopy E-Videos is an open access online section, 回保: reporting on interesting cases and new techniques in gastroenterological endoscopy. All papers include a high quality video and all contributions are freely accessible online. Processing charges apply (currently EUR 375), discounts and wavers acc. to HINARI are available.

This section has its own submission website at https://mc.manuscriptcentral.com/e-videos 